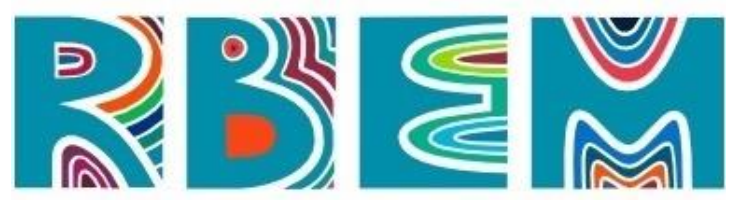

REVISTA BAIANA dE EDUCAÇÃo MATEMÁtICA

ARTIGO

do] https://doi.org/10.47207/rbem.v1i.10317

\title{
O Processo De Construção De Um Material Educacional Na Perspectiva Da Educação Matemática Inclusiva Para Um Aluno Autista
}

\author{
PINTO, Gisela Maria da Fonseca \\ Professora Adjunta do Departamento de Matemática da Universidade Federal Rural do Rio de Janeiro, campus \\ Seropédica. Doutora pelo Programa de Pós-Graduação em Ensino de Matemática da Universidade Federal do \\ Rio de Janeiro (PEMAT/UFRJ). \\ ORCID: https://orcid.org/0000-0002-2468-5361. E-mail: gmfpinto@gmail.com .
}

GUIMARÃES, Amália Bichara

Universidade Federal do Rio de Janeiro (UFRJ). Especialista em Ensino de Matemática pela Universidade Federal do Rio de Janeiro (UFRJ). Mestranda do Programa de Pós-Graduação em Educação em Ciências e Matemática da UFRRJ.

ORCID: https://orcid.org/0000-0002-2160-540X. E-mail: amaliadeguimaraes@ yahoo.com.br.

Resumo: Este trabalho relata uma experiência da mestranda/preceptora/docente em uma escola regular de educação básica junto a residentes do programa de Residência Pedagógica em Matemática da Universidade Federal Rural do Rio de Janeiro, polo Seropédica, no biênio 2018/2019, tendo um aluno autista incluído em uma turma de $8^{\circ}$ ano do ensino fundamental II. Há uma breve fundamentação teórica sobre formação docente para inclusão. Em seguida, são apresentados alguns aspectos relevantes sobre o programa de Residência Pedagógica, destacando a articulação entre formação e prática docente e a caracterização da pesquisa em desenvolvimento. Apresentamos, resumidamente, as análises dos resultados a partir de excertos dos relatórios de residentes/estagiários que evidenciam a relevância da interlocução e do coletivo formado por preceptor e residentes na construção de práticas que incluam o aluno autista. Como resultados, entendemos que conhecer melhor os estudantes autistas e suas especificidades em um trabalho coletivo seja o melhor caminho para a sua inclusão e para a formação inicial docente matemática para a inclusão a partir da vivência e compartilhamento de decisões e situações.

Palavras-chave: Formação de professores; Residência Pedagógica; Autismo; Educação Matemática Inclusiva.

\section{The Process Of Building An Educational Material In The Perspective of Inclusive Mathematical Education For An Autistic Student}

\begin{abstract}
This paper reports an experience of the student/preceptor/teacher in a regular elementary school with residents of the Pedagogical Residency program in Mathematics of the Federal Rural University of Rio de Janeiro, Seropédica pole, in the biennium 2018/2019, with an autistic student included in an 8th grade class of elementary school II. There is a brief theoretical foundation on teacher training for inclusion. Then, some relevant aspects about the Pedagogical Residency program are presented, highlighting the articulation between teacher training and practice and the characterization of research under development. We briefly present the analysis of the results based on excerpts from the reports of residents/trainees that evidence the relevance of the dialogue and the
\end{abstract}




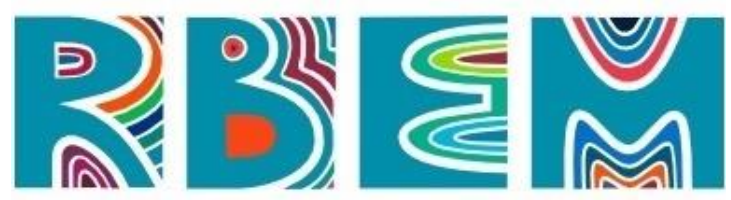

REVISTA BAIANA DE EDUCAÇÃO MATEMÁtICA

collective formed by preceptor and residents in the construction of practices that include the autistic student. As results, we understand that knowing autistic students and their specificities in a collective work is the best way for their inclusion and for the initial mathematical teacher education for inclusion from the experience and sharing of decisions and situations.

Keywords: Teacher training; Pedagogical Residency; Autism; Inclusive Mathematics Education.

\section{El proceso de construcción de un material educativo en la perspectiva de la educación matemática inclusiva para un estudiante autista}

Resumen: Este trabajo reporta una experiencia del estudiante/preceptor/profesor en una escuela primaria regular con residentes del programa de Residencia Pedagógica en Matemáticas de la Universidad Rural Federal de Río de Janeiro, Polo Seropédica, en el bienio 2018/2019, con un estudiante autista incluido en una 8a clase de primaria de la escuela primaria II. Existe una breve base teórica sobre la formación del profesorado para la inclusión. A continuación, se presentan algunos aspectos relevantes sobre el programa de Residencia Pedagógica, destacando la articulación entre la formación y la práctica del profesorado y la caracterización de la investigación en desarrollo. Presentamos brevemente el análisis de los resultados basados en extractos de los informes de residentes/aprendices que evidencian la pertinencia del diálogo y el colectivo formado por preceptor y residentes en la construcción de prácticas que incluyen al estudiante autista. Como resultados, entendemos que conocer a los estudiantes autistas y sus especificidades en un trabajo colectivo es la mejor manera para su inclusión y para la educación inicial del profesorado matemático para la inclusión de la experiencia y el intercambio de decisiones y situaciones.

Palabras clave: Formación del profesorado; Residencia Pedagógica; Autismo; Educación Matemática Inclusiva.

\section{Introdução ${ }^{1}$}

Algumas reflexões se fazem importantes quando começamos a analisar a inclusão de alunos com necessidades educacionais especiais, especificamente o autismo, como a avaliação das potencialidades e limites do aluno autista e seu desenvolvimento no ambiente escolar ou, ainda, a efetividade da inclusão escolar. É notório o desconforto de muitos docentes no que se refere a lecionar, em turmas regulares, em condições como a exposta acima. A pesquisa relatada neste artigo visa compartilhar situação vivenciada por professora de matemática da educação básica imersa exatamente nesse contexto, tendo recebido um aluno autista em uma sala de aula regular, incluído, sem ter orientações ou encaminhamentos de ações que poderiam ser desenvolvidas para promover o crescimento e amadurecimento

\footnotetext{
${ }^{1}$ Este artigo é uma versão revisada e ampliada do texto anteriormente publicado no IX Seminário de Pesquisa em Educação Matemática do Rio de Janeiro.
} 


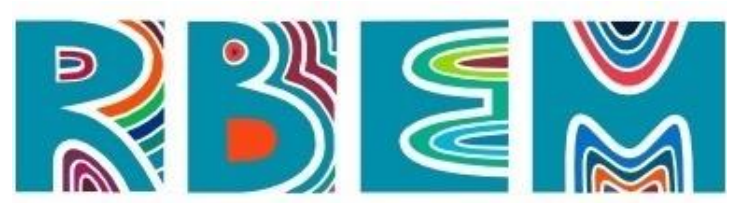

REVISTA BAIANA DE EDUCAÇÃO MATEMÁtICA

escolar desse estudante em parceria com os demais. O coletivo constituído pela professora e por licenciandos em matemática de universidade próxima à escola em questão, licenciandos estes que eram estagiários e/ou residentes no programa Residência Pedagógica, foram o grande norteador nesse processo de inclusão. As discussões conduzidas nas reuniões regulares ocorridas entre docente e discentes residentes modelaram as ações realizadas durante aquele ano.

Nesse contexto, a questão que motiva e norteia essa pesquisa é: como a experiência vivenciada no contexto da Residência Pedagógica pode influenciar a formação desses licenciandos para atuação docente em contexto inclusivo, especificamente com alunos autistas? Tendo se tornado então uma pesquisa de mestrado profissional da professora, a questão aqui apresentada foi motivou a elaboração coletiva de um material educacional, construído aula a aula, reunião após reunião realizada entre a professora de matemática (preceptora) e os residentes, em um trabalho coletivo. As reflexões eram motivadas por discussões sobre as adaptações que poderiam ser realizadas nas atividades propostas em aulas de matemática e que contribuíssem para a inclusão especificamente desse aluno autista. Este material - um caderno pedagógico - foi produzido como o produto educacional proveniente da pesquisa que ora aqui se apresenta.

Por ser uma pesquisa vinculada a um mestrado profissional, como produto educacional, buscamos relatar a docentes de matemática a construção desse percurso, apresentando as atividades adaptadas e os contextos que geraram cada uma delas, na forma de um caderno pedagógico. Nesse produto apresentaremos os registros relacionados a situações vivenciadas durante esse período, as adaptações realizadas e as principais ocorrências segundo os olhares da docente-preceptora e dos residentes-estagiários sobre a sala de aula que incluía o aluno autista. Portanto, o foco da pesquisa, como deve ocorrer em um mestrado profissional, constitui-se como um relato sobre a construção desse produto, ou seja, sobre os encontros entre a professora formada e os professores em formação em uma sala de aula inclusiva possibilitada pelo programa Residência Pedagógica.

Neste texto, será apresentada ao leitor o percurso trilhado pela docente preceptora e pelos discentes residentes, licenciandos em matemática, durante a pesquisa realizada no âmbito do mestrado. Para tanto, apresentamos como panorama teórico as ideias de Vigotski, precursoras já há mais de cem anos, que embasam as ideias de deficiência e inclusão 


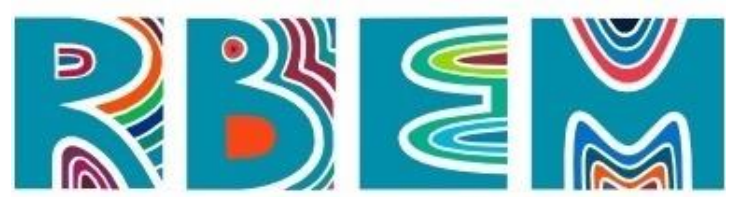

REVISTA BAIANA DE EDUCAÇÃO MATEMÁtICA

apresentadas na pesquisa. Adicionalmente, são oferecidas algumas ideias relacionadas à formação de professores para a inclusão, uma vez que a formação docente perpassa transversalmente a pesquisa, tanto em âmbito inicial (no caso dos licenciandos residentes) quanto em âmbito continuado (no caso da docente preceptora).

Em seguida, a estrutura do programa Residência Pedagógica é apresentada, com vistas a oferecer ao leitor um panorama do cenário de colaboração estabelecido por este programa entre universidade e escola da educação básica, promovendo a convivência frutífera entre docentes da universidade, formadores de professores, docentes da educação básica, preceptores e discentes licenciandos em situação, portanto, de formação docente inicial. Esse cenário, extremamente promissor em uma perspectiva teórica pela formação compartilhada entre diferentes atores com vivências diversificadas em relação ao ensino de matemática na educação básica, mostrou-se decisivo na condução das atividades com o aluno autista incluído na sala de aula regular.

$\mathrm{Na}$ pesquisa adotou-se como dados os textos produzidos pelos residentes e pela preceptora, individual ou coletivamente, orais ou escritos. Esses textos foram analisados a partir da perspectiva da Análise de Conteúdo, de Bardin (1977), emergindo a partir daí quatro categorias, que aparecem descritas na seção Análises. O produto educacional e as considerações finais encerram esse texto, que se delineia então como uma síntese da pesquisa realizada e já finalizada.

\section{Defectologia de Vigotski: deficiência ou diferença?}

A concepção de deficiência de Vigotski foi constituída, também, com base no que era a então defectologia soviética. Defectologia é um termo que hoje soa extremamente desatualizado, e é importante observar que não foi criado por Vigotski, mas ele fez uso, tanto teórico quanto prático, desse termo em uma ressignificação original. Levando em consideração o termo defectologia, Gindis (2003, p. 200, apud STETSENKO, SELAU, 2018, p. 320) explica que:

[d] efectologia é o termo que reflete a área de pesquisa e prática de Vygotsky que é relevante para a educação especial contemporânea e a psicologia escolar. O termo em si parece bastante degradante. (...) este termo não sobreviveria a uma discussão científica no mundo ocidental hoje porque carrega muitas conotações negativas em relação aos indivíduos com deficiência. Ironicamente, o tom negativo do termo em 


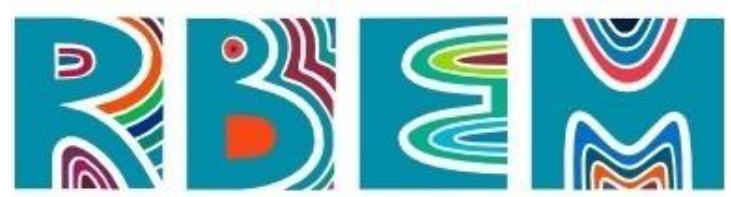

REVISTA BAIANA DE EDUCAÇÃO MATEMÁtICA

si não está de forma algum presente na atitude inspiradora e positiva dos textos de Vygotsky. A palavra defectologia (ou defectology na transliteração em inglês) significa literalmente o estudo do defeito(...)

Os termos defectologia e criança anormal correspondem à terminologia utilizada no início do século XX, quando Vigotski produziu seus textos. Atualmente, seriam equivalentes às expressões deficiência e educação especial e criança com deficiência, respectivamente.

(...) a postulação do desenvolvimento como um percurso tortuoso, atravessado por rupturas e conflitos, e a tese central do autor de que caminhos indiretos de desenvolvimento são possibilitados pela cultura quando o caminho direto está impedido. Isso teria especial importância no caso das crianças com deficiência. $\mathrm{O}$ desenvolvimento cultural seria, assim, a principal esfera em que é possível compensar a deficiência. (...) (VIGOTSKI, 2011, p. 863)

Vigotski insistiu de forma clara e patente que o desenvolvimento extra normativo, hoje denominado deficiência, deveria ser entendido como um processo imerso em práticas socioculturais colaborativas. Portanto, em suas palavras, "o desenvolvimento cultural é a principal área para compensação de extra normatividade, na atualidade, deficiência, quando o desenvolvimento orgânico é impossível; a este respeito, o caminho do desenvolvimento cultural é ilimitado" (VIGOTSKI, 2011, p.90 apud STETSENKO, SELAU, 2018, p. 316).

As pesquisas de Vigotski são absolutamente atuais, mesmo tendo sido desenvolvidas na década de 1930, e coincidem muito com os objetivos da escola inclusiva. Como exemplo podemos citar o enriquecimento do ambiente de aprendizagem, dos recursos e meios a serem utilizados. Colocar o aluno como sujeito do processo, conhecendo-se suas necessidades e promovendo o desenvolvimento cognitivo do aluno são ações pedagógicas que são fundamentais para que se promova a inclusão do estudante. A deficiência não pode mais ser vista como justificativa da estagnação, da discriminação ou exclusão.

O referencial teórico de Vigotski colabora para que seja reconhecido e respeitado o potencial de cada aluno. Cabe a nós, professores, a identificação e reconhecimento das habilidades, potencialidades e capacidades desses estudantes, por menos convencional que possa ser esse percurso, estando atento aos seus atos próprios de pensar, analisar e interagir socialmente.

Esta perspectiva norteou as reflexões conduzidas no seio do grupo constituído pelos membros do programa Residência Pedagógica que participaram da pesquisa aqui apresentada. As ações de ensino que foram realizadas tiveram a intensa participação dos residentes e da 


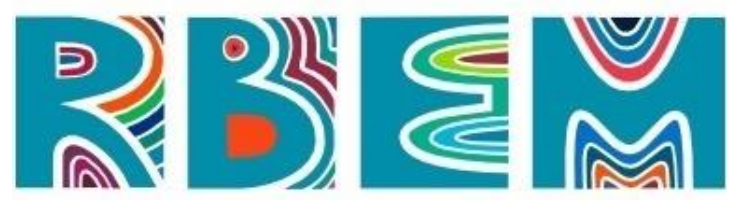

REVISTA BAIANA DE EDUCAÇÃO MATEMÁtICA

docente, no papel múltiplo de preceptora, professora e pesquisadora. Por essa razão, para podermos conduzir as análises pela perspectiva da co-formação ocorrida a partir dessas vivências, tornou-se importante conhecermos alguns princípios e teorias norteadoras da formação docente como apresentados, resumidamente, na próxima seção.

\section{Formação de professores para inclusão}

O processo de construção profissional se dá a partir da integração entre fatores teóricos e práticos, sendo a formação inicial o momento em que o licenciando passa da posição de aprendiz à de professor. Conceitos precisam ser revistos em relação à matemática, à escola e ao ensino: neste momento, muta-se o estudante de matemática da educação básica para o que ensina - o que implica em que necessariamente seja adquirida uma visão ampliada sobre matemática e seu ensino, sobre os estudantes, sobre a estrutura escolar, além de diversos outros aspectos, conforme podemos acessar na Base Nacional Comum Formação (BRASIL, 2019). De acordo com essa normativa, a formação inicial docente implica no desenvolvimento junto ao licenciando de competências específicas e habilidades sediadas em três dimensões: conhecimento profissional, prática profissional e engajamento profissional.

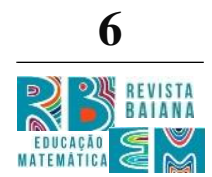

A docência tem sido considerada como "um trabalho social complexo, parte de um projeto educacional de grandes proporções, com interesse em fornecer acesso, através de instituições públicas ou privadas, a toda a população em idade escolar" (MOREIRA; FERREIRA, 2013, p.985). Para esses autores, independente do seu próprio desejo ou expectativa, o professor de Matemática se vê envolvido um processo de natureza social de escolarização básica e que não é hermético aos contextos de lutas sociais e de disputas de interesses políticos, socioculturais ou econômicos.

Essa discussão, portanto, deve fazer parte da formação inicial do professor de matemática, voltada para "uma visão sociológica da educação, a uma análise das políticas públicas para a educação escolar (incluindo as normatizações e as recomendações oficiais), às diferentes percepções das relações entre Estado e educação escolar etc." (CAVALCANTI MOREIRA e FERREIRA, 2013, p.985).

Há todo um acervo de saberes que integram a dimensão do ensino e do conhecimento sobre o aluno pelo professor, de suas peculiaridades e especificidades, que no caso do aluno 


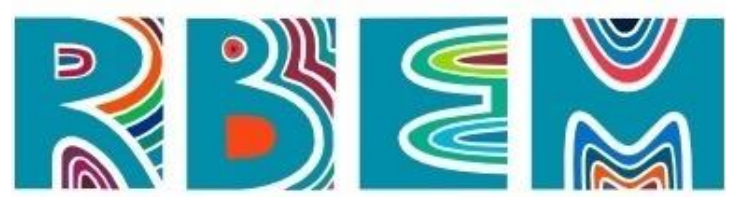

REVISTA BAIANA DE EDUCAÇÃO MATEMÁtICA

com deficiência é bem particular, e que precisa ser conhecido pelo professor. Para sentir-se, minimamente, confiante para exercer suas funções junto às diferenças dentro da escola, faz-se necessário identificar características gerais desse perfil, o que remete ao conhecimento de conteúdo e estudantes.

Conforme Castro et al (2015, p.10) pontuam, é essencial que se reconheça "a importância da formação para professores que abordem especificamente a temática da inclusão nas aulas de matemática”, acrescentando ainda, pouco depois, a emergência de se amplie o entendimento da formação docente, "deixando espaços formais de ensino e a entendendo como um processo contínuo que se fortalece, também, através de momentos reflexivos partilhados entre professores da educação especial, do ensino regular e professores em formação inicial” (p.10), como o que é vivenciado no contexto do Programa Residência Pedagógica.

Comumente, vemos o estudante incluído encarteirado, na perspectiva proposta por Taveira (2008), acaba por ficar isolado em sua carteira, sempre envolvido com uma quantidade de atividades especialmente pensadas para ele e que o mantém passivo durante as aulas e distante dos colegas e das atividades que estes desenvolvem por orientação do professor, apenas por não estarem próximos a uma normalidade exigida hipotética e de um padrão hipotético e não-natural de aprendizagem usualmente almejado por professores e instituições. Esse encarteiramento e as formas de evitar sua ocorrência, certamente pouco proveitosa para o estudante incluído, precisam ser discutidas com os professores em situação de formação inicial, constituindo-se como uma das dimensões dos conhecimentos docentes para o ensino.

À formação inicial docente para o ensino de matemática em uma perspectiva inclusiva cabe também tratar de temas como, por exemplo, a adaptação curricular. De acordo com a proposta de Heredero (2010), essa adaptação, se for promovida, não pode comprometer os estudos posteriores, devendo-se analisar o que será agregado ou retirado, tem-se aqui o conhecimento horizontal do conteúdo. Mas como essa adaptação se dará, por subtração de conteúdos, por escolhas de atividades, por avaliações diferenciadas, são o cerne da questão, constituindo-se em escolhas que definirão os próximos anos do estudante na escola regular. É, 


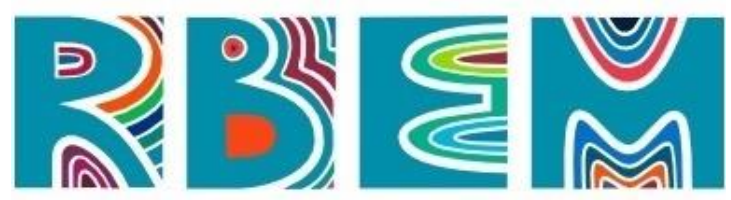

REVISTA BAIANA DE EDUCAÇÃO MATEMÁTICA

portanto, essencial, considerando o filtro da deficiência, conhecer possibilidades diferentes de apresentar aqueles conteúdos aos alunos, assim como conhecer os erros mais frequentes e suas causas - o conhecimento especializado do conteúdo (CASTRO et al, 2015).

Segundo Rodrigues (2014), a formação de professores é, pois, um fértil reduto de esperança e de atuação quando se pretendem alterar os sistemas educativos no sentido de eles corresponderem mais eficazmente à Equidade e à Inclusão. Florian e Spratt (2013, apud RODRIGUES, 2014, p.14) organizam em três temas principais os conteúdos que os cursos de formação de professores deveriam conter em termos da Educação Inclusiva: (1) compreender o ensino, de forma que a diferença seja considerada como um aspeto essencial do desenvolvimento humano; (2) justiça social, de maneira que os professores acreditem em sua própria capacidade e qualificação para ensinar a todas as crianças e (3) tornar-se um profissional ativo, promovendo a concepção de que a profissão docente deve ser desenvolvida de forma a encontrar novas formas de trabalhar com os todos.

Ainda de acordo com esse autor, a formação docente ocorre tanto em disciplinas específicas durante a formação inicial, mas não apenas nessa dimensão: as situações de vivências associadas à atuação profissional agregadas de reflexões, preferencialmente colaborativas, são outro momento de formação enriquecedora e que pode desdobrar-se no desejado engajamento ligado à prática profissional docente. A formação em serviço configura-se como o estabelecimento de uma parceria com vistas ao desenvolvimento profissional que é sentido e desejado pelos formandos. É importante que a formação faça apelo frequente a casos concretos e sobretudo se crie oportunidades de rentabilizar a rede experiencial dos formandos para proporcionar novas aproximações reflexivas e heurísticas com vista a melhor desenvolver a intervenção educacional (RODRIGUES, 2014). Espera-se assim que os novos professores sejam mais inovadores, mais criativos e inconformados do que os professores que há mais tempo estão no ensino.

Skovsmose (2019) propõe que a sala de aula inclusiva seja compreendida como um encontro entre diferenças:

Em geral, sugiro não se ater ao que é considerado normal ou não. Portanto, conceituo a educação inclusiva como uma educação que tenta ir além das diferenças e não como uma educação que tenta incluir os deficientes na normalidade. Essa ideia 


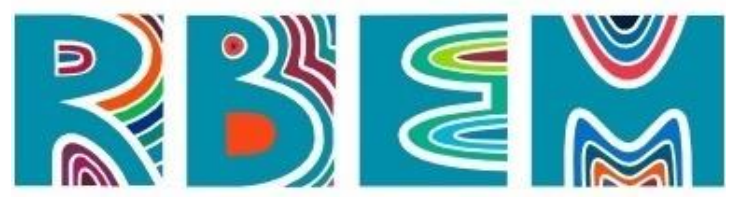

REVISTA BAIANA DE EDUCAÇÃO MATEMÁtICA

nos leva à noção de encontro. Pode-se pensar em encontros entre diferenças como sendo uma categoria humana principal. Essa ideia me inspira a interpretar a educação inclusiva como uma educação que tenta estabelecer encontros entre diferenças. (SKOVSMOSE, 2019, pp.25-26)

De acordo com as ideias de Skovsmose (2019), a educação matemática inclusiva transpõe-se a aspectos objetivos como currículos, conteúdos ou produção de materiais específicos para este ou aquele grupo de estudantes. É nos encontros entre as diferenças que se promove a verdadeira inclusão, no respeito e valorização das diferenças e no empoderamento das minorias. A formação docente para a atuação nessa perspectiva é modelada pela prática, pela vivência, e para ela se volta, promovendo o desejado e necessário engajamento na profissionalização docente. $\mathrm{O}$ ambiente da sala de aula inclusiva no qual compartilhavam o mesmo espaço alunos autistas ou não e professores formados e em formação constitui-se como um ambiente de convivência entre diferentes, configurando-se outrossim como potencialmente formativo, nas perspectivas de Rodrigues (2014) e Skovsmose (2019).

Neste cenário de mudanças há muito o que ser feito e muitas inovações são necessárias. A contribuição das universidades, nesse sentido, inicia-se com a chegada em ambientes de formação docente inicial ou continuada em Matemática de reflexões que antes ficam presas em suas bibliotecas. As políticas inclusivas são uma realidade, não cabe mais a discussão sobre concordar ou não, assim como também não é mais cabível a omissão nas grades curriculares de estudo voltados para a questão da educação matemática inclusiva.

\section{Programa de Residência Pedagógica e Sua Articulação com a Prática Docente em uma Perspectiva Inclusiva}

No âmbito das ações do governo federal, é importante destacar que foi a partir do Decreto $n .^{\circ} 8.752 / 2016$ que a residência pedagógica e a residência docente passaram a ser consideradas ações possíveis para a Política Nacional de Formação dos Profissionais da Educação Básica.

Art. $3^{\circ}$. São objetivos da Política Nacional de Formação dos Profissionais da Educação Básica: [...] VIII - assegurar que os cursos de licenciatura contemplem carga horária de formação geral, formação na área do saber e formação pedagógica específica, de forma a garantir o campo de prática inclusive por meio de residência pedagógica. [...] Art. $8^{\circ}$. O Planejamento Estratégico Nacional, elaborado pelo 


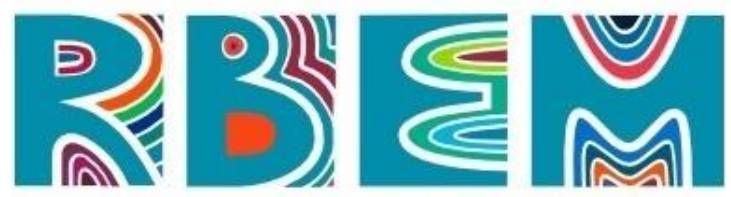

REVISTA BAIANA DE EDUCAÇÃO MATEMÁtICA

\begin{abstract}
Ministério da Educação e aprovado pelo Comitê Gestor Nacional, terá duração quadrienal e revisões anuais, ouvidos os Fóruns Estaduais Permanentes de Apoio à Formação dos Profissionais da Educação Básica, e deverá: [...] IV - promover, em associação com governos estaduais, municipais e distrital, a formação continuada de professores da educação básica mediante integração ensino-serviço, inclusive por meio de residência pedagógica. [...] Art. 12. O Planejamento Estratégico Nacional deverá prever programas e ações integrados e complementares relacionados às seguintes iniciativas: [...] VIII - residência docente, que estimulem a integração entre teoria e prática em escolas de comprovada qualidade educativa. (BRASIL, 2016).
\end{abstract}

Residência educacional, residência pedagógica e residência docente foram as nomenclaturas aplicadas aos Projetos do Senado e sua organização deixam claro sua fragilidade teórico-metodológica segundo o que apontam pesquisadores e estudos sobre formação docente. Mesmo sem a implementação destes projetos ocorrem experiências de residência para formação de professores em instâncias municipais, estaduais e federais, a nível de educação básica e superior.

O Programa de Residência Pedagógica do MEC foi lançado em março de 2018, em edital que definiu a residência pedagógica como "uma atividade de formação realizada por um discente regularmente matriculado em curso de licenciatura e desenvolvida numa escola pública de educação básica, denominada escola-campo" (CAPES, 2018, p. 1). As decisões mais recentes do MEC, no entanto, têm colocado em evidência uma concepção da formação de professores e uma abordagem dos problemas educacionais do país que encontra forte resistência de entidades do setor educacional.

Estruturalmente, o Programa de Residência Pedagógica constitui-se na promoção da imersão reflexiva do licenciando em ambientes de sala de aula da educação básica, sempre junto a um professor da educação básica, denominado preceptor, e em contato regular e permanente com um professor da universidade, coordenador de área do programa na universidade. A realização de reuniões regulares, normalmente semanais, com vistas a aprofundamento teórico, conhecimento e reflexão sobre a prática docente e estabelecimento de conexões com as propostas curriculares e com as questões postas por estudiosos na área de educação matemática norteiam essa formação que é coletiva por natureza, sendo em si um encontro entre diferentes papeis e funções ligadas à formação inicial docente pela prática e na prática.

Embora haja tensões no tocante a formação docente e muitas críticas sobre propostas de formação inicial ou continuada, o Programa de Residência Pedagógica seguindo as 


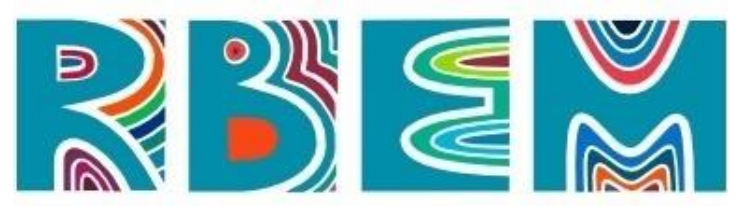

REVISTA BAIANA DE EDUCAÇÃO MATEMÁtICA

orientações da CAPES ou outras iniciativas isoladas no Brasil possibilitam a apropriação de novas formas do fazer do professor, da articulação teoria-prática num processo de aprendizagem coletivo.

A presença do graduando e a sugestão de ações supervisionadas de regência colaboram para uma revisão de sua própria prática docente, num movimento coletivo de novos fazeres e saberes docentes como resposta às necessidades cotidianas.

Ao falar-se de ensino e aprendizagem de Matemática na perspectiva da educação inclusiva, indiscutivelmente, um desafio muito maior estará posto. $\mathrm{O}$ resultado da vivência e interação com outras pessoas, inclusive o aluno diferente será o preparo do professor da educação inclusiva.

Um dos aspectos mais complexos da formação docente é a articulação entre prática e os conteúdos que foram aprendidos durante toda sua formação. Acrescidos a esse fato estão os desafios atuais impostos pela sociedade contemporânea. A residência pedagógica surge como oportunidade para o aluno ser iniciado no cotidiano da escola, o que possibilita ao futuro professor vivenciar as situações nas quais utilizará os conhecimentos sobre o conteúdo a ser ensinado, os princípios gerais de ensino e aprendizagem, uma verdadeira reflexão da prática. E, mais profundamente, numa mudança de perspectiva educacional a fim de abarcar não só os alunos com deficiência, mas todos, reconhecendo-se suas peculiaridades, permitindo-se aos educandos condições verdadeiras de aprendizagem.

\section{Caracterização da pesquisa}

Segundo Lakatos e Marconi (2007, p. 157, apud PRODANOV e FREITAS, 2013 p. 44), a pesquisa pode ser considerada "um procedimento formal com método de pensamento reflexivo que requer um tratamento científico e se constitui no caminho para se conhecer a realidade ou para descobrir verdades parciais.".

$\mathrm{Na}$ busca por compreender a prática pedagógica dos professores, considerando as imagens e as representações como resultados de vivências que partem de sua prática individual e que se estende ao coletivo, optou-se pela abordagem de caráter qualitativo. Todos esses elementos colaboram para responder as indagações e posteriormente, produzir conhecimento no campo da inclusão. 


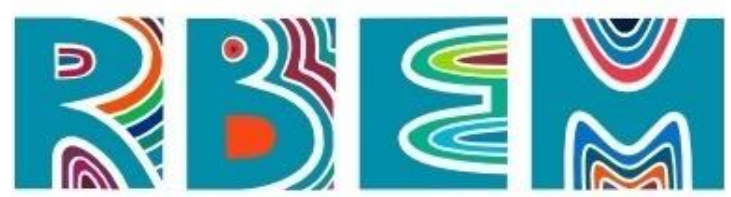

REVISTA BAIANA DE EDUCAÇÃO MATEMÁTICA

Dito isso, é necessário acrescentar que nenhum tipo de pesquisa é autossuficiente. $\mathrm{Na}$ prática, mesclamos todos, acentuando um ou outro tipo. Segundo Demo (2000, p. 22, apud PRODANOV e FREITAS, 2013, p.50),

[...] todas as pesquisas são ideológicas, pelo menos no sentido de que implicam posicionamento implícito por trás de conceitos e números; a pesquisa prática faz isso explicitamente. Todas as pesquisas carecem de fundamento teórico e metodológico e só têm a ganhar se puderem, além da estringência categorial, apontar possibilidades de intervenção ou localização concreta.

No desenho das questões metodológicas, esta pode ser considerada uma pesquisa de natureza aplicada, sob o ponto de vista de seus objetivos trata-se de uma pesquisa explicativa. Segundo Gil (2010, p. 28, apud PRODANOV e FREITAS, 2013, p. 53) visa a identificar os fatores que determinam ou contribuem para a ocorrência dos fenômenos; "aprofunda o conhecimento da realidade porque explica a razão, o porquê das coisas."

Em relação aos procedimentos técnicos, trata-se da pesquisa ex-post-facto, uma vez que analisa situações que se desenvolveram naturalmente após algum acontecimento. Podemos definir pesquisa ex-post-facto "como uma investigação sistemática e empírica na qual o pesquisador não tem controle direto sobre as variáveis independentes, porque já ocorreram suas manifestações ou porque são intrinsecamente não manipuláveis. " (GIL, 2008, p. 54, apud PRODANOV e FREITAS, 2013, p. 6).

Do ponto de vista da abordagem do problema temos uma pesquisa qualitativa. Segundo Pradanov e Freitas (2013, p.70) a interpretação dos fenômenos e a atribuição de significados são básicas no processo de pesquisa qualitativa. Esta não requer o uso de métodos e técnicas estatísticas. O ambiente natural é a fonte direta para coleta de dados e o pesquisador é o instrumento-chave. Neste contexto, compreendemos que a prática do professor e a inclusão do aluno autista estão dentro desta dimensão de algo que não pode ser quantificado, uma vez que traz em seu bojo as atitudes, crenças, desejos, frustações, esperanças.

A coleta de dados aconteceu por meio de diferentes instrumentos: (1) observações da docente/preceptora/pesquisadora acerca das vivências, de cunho descritivo e reflexivo, constituindo-se no que foi chamado diário de campo do aprendiz; (2) registros dos residentes/estagiários que acompanhavam as aulas, acessados por meio de seus relatórios como residentes e como estagiários e (3) entrevista de grupo como técnica para a coleta de dados, inspirada na técnica de Grupo Focal (GF). Utilizaremos essas três técnicas de coletas 


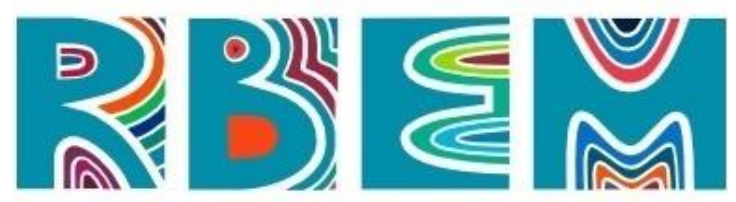

REVISTA BAIANA DE EDUCAÇĀO MATEMÁTICA

de dados com vista a ampliar o universo informacional em torno do objeto de pesquisa (MARCONDES; BRISOLA, 2014).

Essa triangulação de dados não se configura como um método em si, mas antes como uma estratégia de pesquisa que combina métodos, teorias, dados e investigadores, "servindo e adequando-os a determinadas realidades, com fundamento interdisciplinar" (MINAYO et. al., 2005, p. 71, apud MENESES; FUENTES-ROJAS; D’ANTONA, 2018, p.53). Neste sentido, “triangular é combinar e cruzar múltiplos pontos de vista, integrando a visão de vários informantes e empregando uma variedade de técnicas de coleta de dados que acompanha a pesquisa" (p.53).

O contexto da pesquisa consistia em uma turma de $8^{\circ}$ ano em uma escola pública municipal, no turno da tarde, no ano de 2019, contando com 36 alunos. Adotou-se o codinome Francisco para indicar o aluno autista que estava incluído nessa turma. Sobre Francisco, sabia-se apenas que não era assíduo e que, por conta de medicação, muitas vezes dormia em grande parte da aula, no ano anterior, em 2018, ocasião em que estudava pela manhã. A solução encontrada pela escola para minorar esse problema foi transferi-lo para o turno da tarde no ano letivo seguinte. Nunca chegou-se a conseguir apoio especializado para atuar com Francisco; o contato com os pais e responsáveis era bastante reduzido. Não havia um plano individualizado de estudos nem tampouco objetivos previamente discutidos ou definidos. Não havia mediação pedagógica ou acompanhamento especializado.

Durante o ano letivo de 2019 os graduandos participantes do Programa de Residência Pedagógica em Matemática da universidade parceira dessa pesquisa participaram ativamente do planejamento pedagógico, incluindo elaboração de planos de aula, de atividades, de discussão de resultados, da confecção e aplicação de jogos. Esse é um dos objetivos do Programa, contribuir para desenvolver o pensar acerca da educação e a ação em sala de aula. Trata-se de um momento ímpar em possibilidades aos graduandos, onde podem vivenciar a realidade dos diversos espaços educacionais, seus desafios e dificuldades para ofertar uma educação de qualidade.

Ao final de sua participação no programa cada um deles elaborou um relatório de imersão narrando sua experiência em cada etapa. Adicionalmente, alguns dos residentes cursavam também a disciplina de estágio supervisionado IV, dedicada ao contexto da educação matemática especial e inclusiva, o que também gera um relatório final de estágio. 


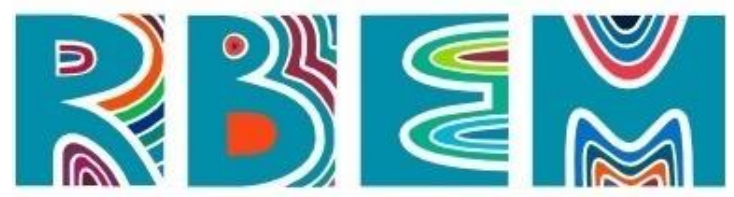

REVISTA BAIANA DE EDUCAÇÃO MATEMÁtICA

Para fins da pesquisa, realizou-se ainda entrevista em grupo com os residentes na perspectiva da entreevista de grupo focal. Percebeu-se em seus relatos a importância de estarem imersos em uma escola regular de educação básica, acompanhar e participar do trabalho realizado com um aluno autista em suas aulas de matemática.

Na próxima seção, apresentaremos as análises que foram realizadas a partir dos dados obtidos na pesquisa, que se fundamentaram na leitura e releitura dos textos produzidos, com vistas a extrair categorias e eixos que se revelaram como norteadores da prática ali vivenciada, no ambiente da sala de aula inclusiva em que estavam todos imersos.

\section{Análises dos resultados}

A análise dos dados coletados foi realizada a partir de três fontes de dados: diário do aprendiz, relatórios residentes/estagiários e entrevistas baseadas na técnica de Grupo Focal (GF). Para tal, escolhemos a Análise de Conteúdos (AC), na perspectiva de Bardin, aplicada a discursos e formas de comunicação diversos.

Foi feita uma leitura detalhada do material, chegando-se à construção das primeiras análises de forma transversal. Após desmembramento, codificação e apropriação desses dados, emergiram as seguintes categorias para análise: Conteúdos; Estratégias de Ensino; Relações entre Teoria e Prática e Impacto e Influências na Vida Profissional. Destaca-se que estas categorias não são necessariamente disjuntas. As categorias de análise dialogam com o caderno pedagógico proposto por serem contribuições oriundas da pesquisa, modelando a sua construção.

$\mathrm{Na}$ categoria Conteúdos, estão ressaltados todos os pontos dos dados que remetem a algum tipo de discussão ou reflexão acerca dos conteúdos a serem trabalhados junto com Francisco. Essas falas trazem contextos de adaptações, principalmente, tanto em relação ao projeto político pedagógico quanto em relação ao currículo ou até mesmo algumas adaptações pensadas no momento da aplicação de atividades em função das reações do aluno.

Os conteúdos trabalhados junto a Francisco eram, inicialmente, os mesmos pensados para a turma inteira. No entanto, em função das suas seguidas ausências ou por conta da forma como estava na sala de aula, muitas vezes foram necessárias algumas adaptações. De acordo com Redig, Mascaro e Dutra (2017, apud SILVA, CRESPO, CAMARGO, 2019.p.84) 


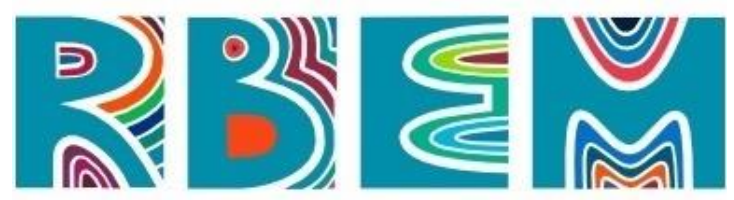

REVISTA BAIANA DE EDUCAÇÃO MATEMÁTICA

"surge a necessidade de encontrar maneiras diferenciadas para que qualquer barreira que um aluno apresente para aprender os conteúdos acadêmicos seja eliminada" ou, pelo menos, reduzida. Foram percebidos, ainda que não explicitamente, alguns perfis de adaptações pelos residentes:

Quando me aproximei com a folha em mãos, abaixou a cabeça e nada mais disse. Resolvemos não repetir a aplicação da atividade, mas separar os conteúdos em diversas outras. (Diário do Aprendiz, 2019)

(...) ainda no segundo bimestre tentamos abordar o conteúdo (medidas de ângulos) só que usando os ponteiros de um relógio. Tínhamos um relógio com o emblema do time de futebol Fluminense. Francisco parecia ter gostado da surpresa. (Diário do Aprendiz, 2019)

Para Orrú (2019) criar condições para um aprendizado de qualidade para o aprendiz autista é se envolver com uma multiplicidade de ações sempre primando pela constituição da consciência íntima do aprendiz sobre si próprio e aquilo que lhe diz respeito. No contexto da inclusão dos alunos autistas em salas de aulas regulares, uma das principais adaptações realizadas pelo professor é a adaptação curricular, que engloba respostas educativas que buscam o favorecimento a todos os alunos com a flexibilização do currículo escolar (BRASIL, 1998; ZANATA, 2005). Foi fundamental para o aluno autista uma visão mais positiva a seu respeito, pela adoção de uma postura respeitosa, pela elaboração de material individual que o incentivasse a tentar, que possibilitasse sua formação.

Na categoria Estratégias de Ensino, entendendo-se a utilização dessas técnicas pelos professores com o objetivo de ajudar o aluno a construir seu conhecimento, analisamos adaptações do método de ensino e da organização didática. Adaptar o método de ensino às necessidades de cada aluno é, na realidade, um procedimento fundamental na atuação profissional de todo educador, já que o ensino não ocorrerá, de fato, se o professor não atender ao jeito que cada um tem para aprender (ARANHA, 2000).

A construção e adaptação de atividades pensadas para o estudante autista incluído na turma forma construídas e aplicadas coletivamente por preceptora e residentes, estes últimos atuando, ainda como mediadores, acompanhando o estudante na realização das atividades. Os excertos a seguir apresentam algumas reflexões dos residentes sobre essas questões:

Eu lembro que logo no início né, a senhora falou que a gente precisava arrumar os objetivos de ensino, a gente precisava adaptar todas as atividades para que ele pudesse participar (...) (Excerto de fala de um residente durante entrevista em grupo) 


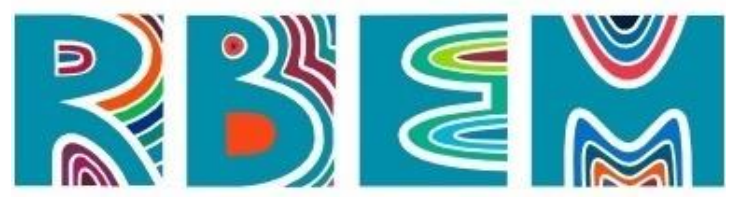

REVISTA BAIANA DE EDUCAÇÃO MATEMÁtICA

(...)não tinha nada adaptado, era uma prova assim, muito, muito complexa, eu fiquei sem saber o que fazer com ele, ele também não conseguiu fazer. Precisa ter esse cuidado, sabe? Não de fazer diferença, mas precisa ter um olhar especial, né? (Excerto de fala de um residente durante entrevista em grupo)

Nesses relatos, e em outros em que a dimensão desse texto não permite inserir, percebe-se a preocupação em considerar as singularidades do aprendiz, em delinear por meio do conhecimento cotidiano junto a esse aprendiz o percurso educacional mais adequado, concordando com Orrú (2019).

Eu lembro uma vez que ele foi fazer, eu acho que foi Olimpíada de Matemática, gente ele foi incrível, ele conseguia responder as coisas super-rápido, como a R7 falou, as contas de multiplicação, de área, ele era incrível! Mas ele precisava ter esse cuidado é, das atividades adaptadas. (Excerto de fala de um residente durante entrevista em grupo)

(...) e aí nós ficamos sentados com ele tentando convencê-lo a fazer a atividade, mas nesse dia, aparentemente, ele estava bem resistente em participar da aula, em fazer a atividade, então era um dia que ele não estava muito aberto ao diálogo nenhum. (Excerto de fala de um residente durante entrevista em grupo)

As situações observadas pelos residentes e com as quais, ao se depararem, buscavam solucionar a partir das interações com os colegas residentes e também com a docente preceptora constituem-se como um campo rico de crescimento e aprendizagem para todos, no qual revelam-se possibilidades de que um espaço educacional que seja enriquecido de ações pedagógicas dialógicas, nas quais as diferenças possam ser proveitosas para todos, inclusive

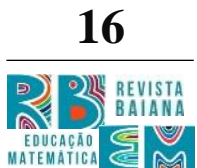
para o próprio professor.

Em Relações entre Teoria e Prática procuramos mostrar que a função do diagnóstico médico no espaço escolar, sendo usado para rotular, para designar indivíduos, pode ser substituído ou pelo menos acrescido de considerações das especificidades do aluno autista por parte do professor, levando a ações que possam construir um ambiente ainda mais propício para o desenvolvimento do aluno.

Considerando o contato com o aluno ao longo do ano, destacamos experiências diferentes em relação a sua convivência em sala de aula, buscamos entender as peculiaridades do aluno, respeitando suas limitações. Demonstramos compreender as especificidades do aluno, sem repreendê-lo por essas especificidades de alguma forma. O primeiro passo para esse processo é a observação, que permite ao professor identificar detalhes importantes sobre o aluno que o ajudará a lidar da maneira mais adequada.

Os principais sinais que caracterizam uma pessoa com autismo são traços bem marcantes no Francisco, tais como dificuldade na socialização, movimentos e falas repetitivas, alterações de comportamento e humor, dificuldade para olhar nos olhos 


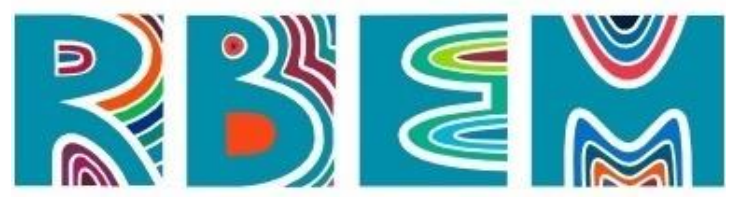

REVISTA BAIANA DE EDUCAÇÃO MATEMÁtICA

e desvio de atenção em ambientes barulhentos." (excerto de relatório final de um residente)

No entanto, pude perceber que em determinados momentos, o aluno desviava o foco da atividade para os outros acontecimentos da sala, ou seja, as conversas dos outros alunos (qualquer outro tipo de barulho mais intenso, ou então chegada de uma pessoa diferente) faziam com que ele se desconcentrasse da atividade principal com muita facilidade, o que de certa forma prejudicou o desenvolvimento na questão do tempo. (excerto de relatório final de um residente)

Ah! Esse aqui é o.... eu não me recordo o nome...Jordan. Francisco ficou falando: Jordan, Jordan, Jordan fala oi para ela! E ele ficava fazendo falas repetitivas às vezes né, e depois ele começou a falar de futebol, que ele torce para o Fluminense, que não sei o quê... (excerto de relatório final de um residente)

Em relação às suas sensações e emoções sempre tivemos dúvida porque havia pouca comunicação verbal, algo que era bem característico dele e dos autistas de modo geral. (Diário do Aprendiz, 2019)

O primeiro contato com o aluno foi feito através de algumas conversas, onde me apresentei e busquei sempre respeitar o espaço dele, para que aos poucos ele fosse se familiarizando com a minha presença. (excerto de relatório final de um residente)

O trabalho pedagógico junto a alunos autistas quase sempre é desafiado pelas singularidades próprias deste aprendiz, além das possíveis dificuldades no processo de aprender, na complexidade das interações sociais e na comunicação. (ORRÚ, 2019, p.163).

Através da prática docente, dos incentivos, notamos mudanças na interação dos alunos dentro de sala de aula, além da que envolve professor e aluno autista apenas. Tal incentivo é importante, pois essa troca de experiências, a cooperação e a solidariedade entre os alunos propiciam o desenvolvimento dos discentes em diversos aspectos cognitivos, sociais e emocionais.

$\mathrm{Na}$ experiência com Francisco, os residentes desempenharam também a função de mediadores, estimulando a comunicação e a interação social, atribuindo significado aos conteúdos trabalhados, levando o aprendiz a apropriar-se dos conceitos trabalhados. Não discutiremos aqui as diretrizes que abordam sobre esse assunto por serem amplas e não aplicáveis nesse contexto. Apesar das garantias legais, Francisco não contava com um mediador para auxiliá-lo nas atividades escolares. Afirmamos que só foi possível conseguir sua participação por ter sido acompanhado, individualmente, por um residente. A mesma mediação ocorrida durante as aulas foi necessária durante as atividades avaliativas previstas no calendário escolar da rede municipal onde Francisco estava matriculado. 


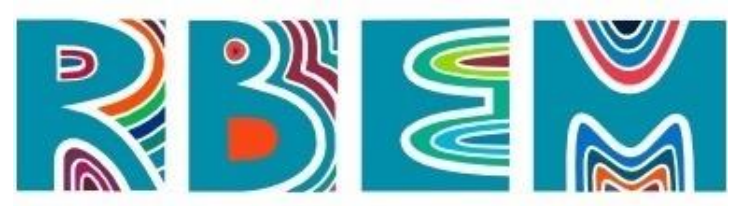

REVISTA BAIANA DE EDUCAÇÃO MATEMÁTICA

Na categoria Impacto e Influências na Vida Profissional analisamos as experiências vivenciadas pelos residentes durante o período de imersão, as reflexões oriundas das atividades práticas aplicadas a Francisco e os momentos de estudo, de planejamento, de busca de orientações. Acreditamos terem sido possibilidades formativas inclusivas. Surgem nessa categoria o reconhecimento dessa experiência para sua formação profissional e o questionamento de não haver, segundo o exposto pelos residentes/estagiários, uma política bem definida de formação na perspectiva inclusiva no curso de licenciatura em Matemática a que faziam parte, a menos de iniciativas isoladas de docentes.

Eu acho que foi esse olhar para a individualidade do aluno, esse contato com o Francisco me trouxe. (...) O seu olhar para o aluno me fez aprender muito, para minha vida mesmo, de como trabalhar mesmo, de tentar buscar o melhor para o aluno. (Excerto de fala de um residente durante entrevista em grupo)

nunca foi assim você era a orientadora da escola né, a professora preceptora, mas você sempre sentou com a gente e falou olha: _ nós temos essa situação e o que nós podemos fazer para resolver essa situação, como nós podemos trabalhar para resolver essa situação? Então eu acho que essa coisa do diálogo e sempre aquela busca de entender onde nós queríamos chegar, qual era o caminho que nós tínhamos que percorrer com as atividades, com a preparação, com todas essas etapas de construção mesmo (excerto da fala de um residente durante entrevista em grupo)

O Projeto Residência Pedagógica foi uma oportunidade ímpar na minha trajetória acadêmica. Através do projeto pude ter diversas vivências que acrescentaram muito na minha vida profissional, pois tive a oportunidade de viver o dia a dia de um professor regente e aprender como as coisas funcionam realmente (excerto de relatório final de um residente)

Ressalte-se, nesse ínterim, o foco da disciplina de Estágio Supervisionado IV, no qual alguns dos nossos entrevistados estavam matriculados durante o período observado, e que tem como um dos objetivos a promoção de reflexões acerca da educação matemática inclusiva.

A partir do momento que começam a dialogar, a trocar experiências, a contextualizar os fatos que ocorrem diariamente, a perceber que o contato com o outro é essencial para o ser humano, internalizamos tais conhecimentos e vivências, transcendendo o conhecimento advindo da racionalidade mecanizada instituída até então (ORRÚ, 2012). O êxito do trabalho do professor, centrada nas relações sociais e na mediação com alunos autistas, é consequência do trabalho realizado pelo professor (ORRÚ,2012, p. 159). 


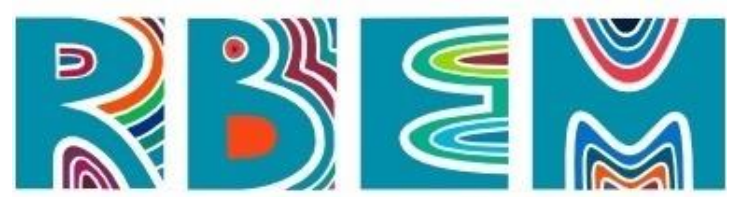

REVISTA BAIANA DE EDUCAÇÃO MATEMÁTICA

Percebemos na fala dos residentes quão importante foi a imersão no programa de residência e vivenciar, experimentar todos os desafios da inclusão, do dia a dia em sala de aula. Um dos residentes relata a relevância de uma das poucas oportunidades que teve durante sua licenciatura, as reflexões a partir do que viveu na escola, ao que observamos em Francisco. Acreditamos que cada residente a partir de tudo que foi experimentado poderá ter despertado em si o princípio da inclusão. Segundo Peebles e Mendaglio (2014, apud BORGES, CYRINO, NOGUEIRA, 2020), as atitudes futuras dos professores, ao se depararem com estudantes com deficiência, serão mais favoráveis se, já na formação inicial, os futuros educadores tiverem tido contato com experiências de ensino para esses alunos.

Sabemos que esse assunto não se esgota aqui, que ainda há muito a ser discutido sobre a inclusão de alunos atípicos, sobre práticas formativas inclusivas e várias outras falhas no que tange o ensino e aprendizagem de Matemática. No entanto, antes de esgotar o assunto, precisamos gerar mais e mais discussões e reflexões, sempre conduzidas de maneira colaborativa, promovendo um saber que nasce na coletividade e para ela se direciona, em busca sempre de situações pedagógicas matemáticas que de fato promovam o crescimento e amadurecimento matemático de cada estudante, de acordo com suas potencialidades e não tomando como parâmetros norteadores da prática as suas impossibilidades.

\section{Considerações finais}

Com uma abordagem qualitativa, nessa pesquisa combinou-se, simultaneamente, análise documental; tendo com dados da pesquisa registros pessoais numa tríade de visões, ou seja, como professora, preceptora e pesquisadora, anotações dos estagiários/residentes e transcrição de entrevistas usando a técnica de Grupo Focal (GF) relacionados à atuação e formação docente em matemática junto a um aluno autista incluído numa turma de $8^{\circ}$ ano com 36 alunos em escola regular. Os fatos aqui descritos nos permitiram analisar e descrever a prática pedagógica da pesquisadora/preceptora conduzida em parceria junto a um grupo de alunos do programa de Residência Pedagógica.

As análises foram realizadas a partir da interlocução entre o que foi levantado sobre a formação inicial docente para a ação em ambientes inclusivos e ainda a partir da perspectiva da inclusão e do levantamento de pesquisas e fundamentação teórica sobre o autismo. Os 


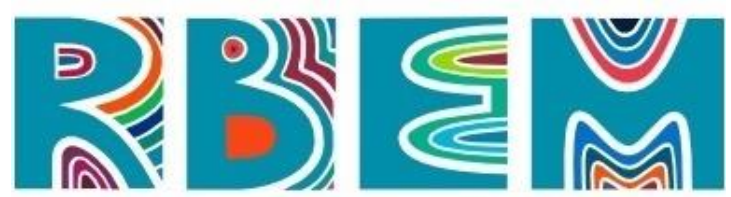

REVISTA BAIANA DE EDUCAÇÃO MATEMÁtICA

eixos de análise que emergiram a partir da imersão nos dados, pela perspectiva da Análise de Conteúdo, foram Conteúdos; Estratégias de Ensino; Relações entre Teoria e Prática e Impacto e Influências na Vida Profissional.

Percebe-se que o professor, ao atuar profissionalmente, precisa considerar a importância da diversidade no processo de ensino-aprendizagem, sendo capaz de construir estratégias de ensino, adaptando atividades e conteúdo. Esta prática pedagógica pode ser adotada de modo geral tendo como meta diminuir a evasão e fracasso escolar. Essa demanda foi percebida e destacada pelos alunos residentes a partir da observação de todo trabalho realizado com Francisco.

Cabe aqui comentar ainda que o desenvolvimento dessa capacidade de construção e remodelação em tempo real de estratégias e recursos de ensino dificilmente será possível de ser ensinada durante um curso de formação inicial de professores. As vivências, as experiências, o olhar para a prática e a oportunidade da participação em situações voltadas para a prática docente, em interlocução frequente com professores e formadores de professores, reconhecendo suas dúvidas e as maneiras com que estes se posicionam e buscam auxílio e orientação é o que grandemente contribuirá para que a tão almejada formação inicial em docência matemática para a atuação em contexto inclusivo possa ser minimamente eficaz.

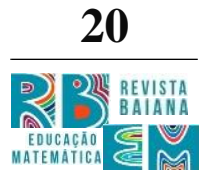

O produto educacional traz em seu âmago essas reflexões organizadas de maneira a contribuir junto a professores que têm alunos autistas incluídos em suas salas de aula, para que possam encontrar nessa experiência algum apoio e subsídio para que busquem eles mesmos também estabelecer estas parcerias para tornar o trabalho de ensinar matemática em contexto inclusivo mais frutífero para todos. .

A experiência com Francisco junto à preceptora e os residentes sugere que não há um método ótimo ou mesmo uma forma de ensinar em disciplinas durante a formação inicial o como o professor deve desenvolver sua ação pedagógica junto ao aprendiz autista. Antes disso, pode-se fomentar busca pelo respeito de necessidades individuais, longe das tradicionais padronizações. O espaço escolar deve ser dedicado a momentos de aprendizagem, a práticas pedagógicas inovadoras desenvolvidas e implementadas em conjunção com outros atores para além do docente.

Cabe ressaltar aqui a relevância de que tal concepção transcenda a esfera dos alunos que divergem dos padrões hipotéticos, mas antes, que o respeito e o reconhecimento das 


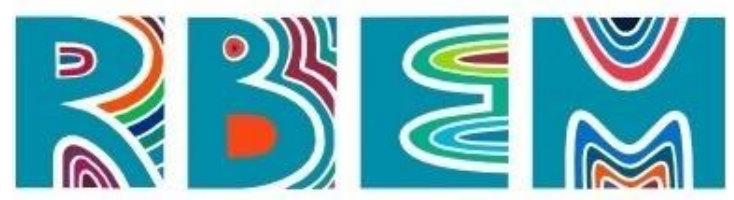

REVISTA BAIANA DE EDUCAÇÃO MATEMÁTICA

individualidades seja uma realidade para todos os estudantes em sala de aula. Cada vez mais caminhamos nessa direção, na percepção das diferenças e do quanto as tentativas de homogeneização são artificiais e pouco construtivas.

\section{Referências}

ARANHA, M. S. F. Projeto Escola Viva garantindo o acesso e permanência de todos os alunos na escola: Alunos com necessidades educacionais especiais/ Adaptações Curriculares de Pequeno Porte. Brasília: MEC/SEE, 2000. Disponível em:

http://www.dominiopublico.gov.br/download/texto/me000449.pdf. Acesso em: 08 out. 2020.

BALL, D.; M.H. THAMES; G. PHELPS. Content Knowledge for teaching: What makes it special? Journal of Teacher Education, v.59, n.5, p.389-407, 2008.Disponível em: https://www.researchgate.net/publication/255647628_Content_Knowledge_for_Teaching_W hat_Makes_It_Special Acesso em: 12 abr.2018

BARDIN, L. (1977). Análise de Conteúdo. Lisboa: Edições 70. Disponível em: https://www.ets.ufpb.br/pdf/2013/2\%20Metodos\%20quantitat\%20e\%20qualitat $\% 20$ \%20IFES/Livros\%20de\%20Metodologia/10\%20-\%20Bardin,\%20Laurence\%20\%20An\%C3\%A1lise\%20de\%20Conte\%C3\%BAdo.pdf. Acesso em: 19 ago. 2020.

CAPES. Coordenação de Aperfeiçoamento de Pessoal de Nível Superior. Portaria n. ${ }^{\circ}$ 206, de 21/10/2011. Diário Oficial da União, Brasília, DF, Ministério da Educação, 2011. Disponível em: https://www.normasbrasil.com.br/norma/portaria-206-2011_231356.html Acesso em: 14 maio 2020.

FARIA, J.B.; PEREIRA, J.E.D. Residência Pedagógica: afinal, o que é isso? R. Educ. Públ. Cuiabá, v. 28, n. 68, p. 333-356, maio/ago. 2019. Disponível em:

http://periodicoscientificos.ufmt.br/ojs/index.php/educacaopublica/article/view/8393 Acesso em: 13 maio 2020.

GIL, Antonio Carlos et al. Como elaborar projetos de pesquisa. São Paulo: Atlas, 2010.

GINDIS, B. Remediation Through Education: Sociocultural Theory and Children with Special Needs. In: KOZULIN, A. et al. Vygotsky's Educational Theory in Cultural Context. New York: Cambridge University Press, 2003. p. 200-221 apud STETSENKO, A.; SELAU, B. A abordagem de Vygotsky em relação à deficiência no contexto dos debates e desafios contemporâneos: Mapeando os próximos passos. Educação revista quadrimestral. Porto Alegre, v. 41, n. 3, p. 315-324, set. - dez. 2018. Disponível em:

http://revistaseletronicas.pucrs.br/ojs/index.php/faced/article/viewFile/32668/17610Acesso em: 06 abr .2020.

MARCONDES, F.G.V.; LIMA, P.C.; A busca pela receita de inclusão na formação de professores: o olhar para o outro e a empatia matemática como um caminho possível. Boletim 


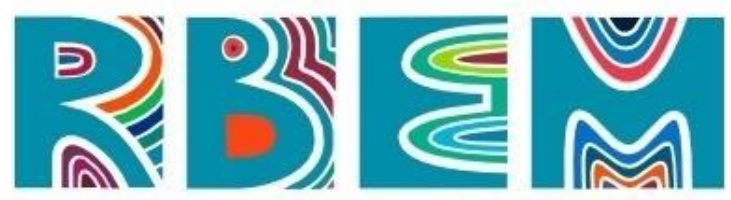

REVISTA BAIANA DE EDUCAÇÃO MATEMÁTICA

GEPEM. n. 76, 2020. Disponível em: http://costalima.ufrrj.br/index.php/gepem/article/view/513/888. Acesso em: 01 out. 2020.

MENESES, A. F. P..; FUENTES-ROJAS, M.; D’ANTONA, A.O. Triangulação de métodos: estratégia metodológica na pesquisa interdisciplinar sobre o cuidado às pessoas vivendo com hiv/aids.. Revista Espaço de Diálogo e Desconexão-REDD. Vol.10, nº.1, p. 52-64, 2018. Disponível em: https://periodicos.fclar.unesp.br/redd/index Acesso em: 04 ago. 2020.

MOREIRA. P..; FERREIRA., A.C. O Lugar da Matemática na Licenciatura em Matemática Boletim de Educação Matemática, vol. 27, núm. 47, dez., 2013, pp. 985-1005 Universidade Estadual Paulista Júlio de Mesquita Filho Rio Claro, Brasil. Disponível em: https://www.redalyc.org/pdf/2912/291229747014.pdf Acesso em: 05 ago. 2020.

PLETSCH, M. D (org.).; DAMASCENO, A. (org.) Educação Especial e Inclusão Escolar Reflexões sobre o Saber Pedagógico. EDUR: Editora da Universidade Federal Rural do Rio de Janeiro, Seropédica, RJ. Disponível em: http://r1.ufrrj.br/im/oeeies/wpcontent/uploads/2015/03/Livro-Educa\%C3\%A7\%C3\%A3o-Especial-Inclus\%C3\%A3oEscolar.pdf Acesso em: 20 abr.2020.

PLETSCH, M. D. A formação de professores para a educação inclusiva: legislação, diretrizes políticas e resultados de pesquisas. Educar, Curitiba, n. 33, p. 143-156, 2009. Disponível em: https://www.scielo.br/pdf/er/n33/10.pdf. Acesso em: 09 maio 2020.

PLETSCH, M. D.; LIMA, M. F.C. A Inclusão Escolar de Alunos com Autismo: Um Olhar sobre a Mediação Pedagógica. I Seminário Internacional de Inclusão Escolar: práticas em diálogo. CAP - UERJ, 2014, Rio de Janeiro, RJ. Anais eletrônicos... Disponível em: http://www.cap.uerj.br/site/images/stories/noticias/4-Pletsch_e_Lima.pdf Acesso em: 01 maio 2020.

PLETSCH, M. D.; SOUZA, F. F.; ORLEANS, L.F.. A diferenciação curricular e o desenho universal na aprendizagem como princípios para a inclusão escolar. Revista Educação e Cultura Contemporânea, v. 14, n. 35, 2017. Disponível em: http://periodicos.estacio.br/index.php/reeduc/article/viewArticle/3114 Acesso em: 21 abr.2020.

PRODANOV, C. C.; FREITAS, E.C. Metodologia do trabalho científico [recurso eletrônico]: métodos e técnicas da pesquisa e do trabalho acadêmico, 2. ed. - Novo Hamburgo, Rio Grande do Sul, 2013. Disponível em: http://www.feevale.br/Comum/midias/8807f05a-14d0-4d5b-b1ad-1538f3aef538/Ebook\%20Metodologia\%20do\%20Trabalho\%20Cientifico.pdf. Acesso em: 26 maio 2020.

RODRIGUES, D. Os Desafios da Equidade e da Inclusão na Formação de Professores. Revista Nacional e Internacional de Educación Inclusiva. v. 7, n. 2, 2014. Disponível em: https://dialnet.unirioja.es/servlet/articulo?codigo=4773176. Acesso em: 29 jul. 2020. 


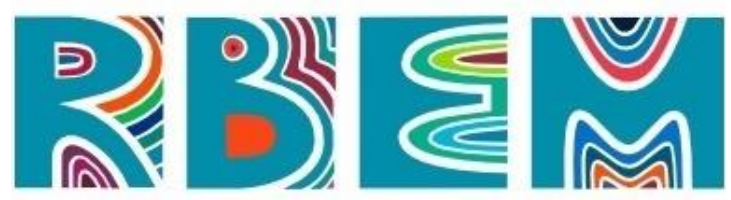

REVISTA BAIANA DE EDUCAÇÃO MATEMÁtICA

SHULMAN, L.S.Knowledge an teaching: Foudations of the new reform. Harvard Educational Review, Harvard, v.57, n.1, p.1-22,1987.Disponível em: https://people.ucsc.edu/ ktellez/shulman.pdf Acesso em: 12 abr. 2018

STETSENKO, A.; SELAU, B. A abordagem de Vygotsky em relação à deficiência no contexto dos debates e desafios contemporâneos: Mapeando os próximos passos. Educação revista quadrimestral. Porto Alegre, v. 41, n. 3, p. 315-324, set. - dez. 2018. Disponível em: http://revistaseletronicas.pucrs.br/ojs/index.php/faced/article/viewFile/32668/17610 Acesso em: 06 abr .2020.

VIGOTSKI, L. S. A defectologia e o estudo do desenvolvimento e da educação da criança anormal. Educação e Pesquisa, São Paulo, v. 37, n. 4, p. 861-870, dez. 2011. Disponível em: http://www.scielo.br/pdf/ep/v37n4/a12v37n4.pdf Acesso em: 28 abr.2020.

Artigo submetido em: 18/11/2020

Artigo aceito em: 22/12/2020 